\title{
Review and pictorial essay on complications of bariatric surgery
}

\author{
(iD Laio Bastos de Paiva Raspante \\ (iD) Ávanny do Carmo Barquette 1 \\ Demília Guerra Pinto Coelho Motta² \\ (iD) Marcelo Almeida Ribeiro ${ }^{2}$ \\ (D) Laura Filgueiras Mourão Ramos² \\ (iD) Wanderval Moreira ${ }^{2}$
}

1. Médico com Pós-Graduação em Radiologia e Diagnóstico por Imagem Ciências Médicas de Minas Gerais (PGCM-MG) - Fundação Educacional Lucas Machado (Feluma), Belo Horizonte, MG, Brasil 2. Médico Radiologista da Rede MaterDei de Saúde - Radiologia, Belo Horizonte, MG, Brasil

http://dx.doi.org/10.1590/1806-9282.66.9.1289

\begin{abstract}
SUMMARY
Obesity is a chronic disease characterized by excess fat in the body and a real public health problem. Bariatric surgery, in recent decades, has gained space in its treatment due to the efficiency obtained in weight loss and significant reduction of the related comorbidities. The most commonly performed bariatric procedures include Roux-en-Y gastric bypass, adjustable gastric band, and laparoscopic sleeve gastrectomy. Possible complications described include fistulas, dehiscence, marginal ulcers, intestinal obstruction, internal hernias, and anastomotic stenosis. These complications may have unfavorable clinical outcomes since symptoms are often nonspecific. Abdominal computed tomography (CT) is an important tool in the evaluation of postoperative complications, both in the immediate and late postoperative status of patients undergoing such a procedure. We analyzed the most illustrative tomographic findings of the different complications after reducing gastroplasty in 203 patients without distinction of age or gender. Correct interpretation requires radiologists to understand the surgical technique since postoperative anatomy and surgery-specific complications may be obstacles to proper interpretation.
\end{abstract}

KEYWORDS: Gastroplasty. Bariatric surgery. Postoperative complications. Tomography, X-ray computed.

\section{INTRODUCTION}

Obesity is a chronic disease characterized by excess adipose tissue in the body. It has reached epidemic proportions, making it a public health problem. Over the last decades, bariatric surgery has gained space for the treatment of morbid obesity and the substantial reduction of comorbidities, mainly due to unsatisfactory results from the conventional clinical treatment ${ }^{1.2}$.
The most commonly performed bariatric procedures include the laparoscopic Roux-en-Y gastric bypass, the laparoscopic adjustable gastric banding, and the laparoscopic vertical sleeve gastrectomy ${ }^{3-5}$. Among the possible complications described in the literature are fistulas, dehiscences, marginal ulcers, intestinal obstruction, internal hernias, and anastomotic stenosis ${ }^{6-8}$. These complications may present 
unfavorable outcomes since the clinical symptoms are often nonspecific and include: abdominal pain and distension, nausea, and vomiting.

Postoperative imaging studies, CT in particular, for bariatric procedures are typically carried out to identify the integrity and patency of the anastomosis and to identify such complications ${ }^{3.4}$. An adequate evaluation requires radiologists to understand the surgical technique since the complex post-surgical anatomy and the specific complications from surgery make the interpretation more difficult. Finally, the unfavorable outcomes of such complications can be minimized, particularly through an early evaluation by imaging studies, therefore better management is obtained through a prompt assessment by a radiologist.

\section{METHODS}

The objective of this study was to review the main complications and their radiological aspects found post-operatively in patients who underwent Rouxen-Y gastric bypass (RYGB), laparoscopic adjustable gastric banding, laparoscopic vertical sleeve gastrectomy. We analyzed, retrospectively, the abdomen computed tomography images that were most illustrative of different complications after bariatric procedures completed in 203 patients from August 2012 to July 2019. The analysis was carried by a physician of the Radiology and Imaging Diagnosis Department of the Rede Mater Dei. The images were stored in the PACS (Picture Archiving and Communications System) and obtained from a multislice/helical computed tomography device without or without injection of intravenous non-ionic iodinated contrast and/or associated with the ingestion of iodinated contrast diluted in water. The main complications observed were: internal hernias, adherence or bridles, twisting of the root of the mesentery, intestinal intussusception, fistula, and anastomotic stenosis.

\section{DISCUSSION}

Obesity and its related health complications have reached epidemic proportions ${ }^{2-6}$. The association between obesity and diabetes type II, increased cardiovascular risk for hypertension, hypercholesterolemia, sleep apnea, osteoarthritis, and other complications such as "metabolic syndrome" and cancers is well established. Such an increase in the incidence of the obese population, in addition to increasing rates of morbidity, is related to higher health-related costs, both in direct spending for the treatment of obesity and in indirect costs due to the decrease in productivity and absenteeism at work' 1 .

It has been demonstrated that weight reduction, even at a small level, is beneficial. The patients who are candidates for surgical treatment are those with a body mass index (BMI) greater than $40 \mathrm{~kg} / \mathrm{m}^{2}$, BMI greater than $35 \mathrm{~kg} / \mathrm{m}^{2}$ associated with comorbidities such as those described above, in addition to failure in the clinical treatment. Bariatric surgery has demonstrated superiority over non-surgical treatments, producing lasting weight loss in comparison to changes in lifestyle and with a greater impact on obesity-related comorbidities.

Roux-en-Y gastric bypass is currently one of the most used procedures, and it can be accomplished through laparoscopy or open surgery. The gastric bypass, in this technique, consists in reducing the extent of the gastrointestinal tract, excluding from the food transit part of the stomach, the duodenum, and usually about $40 \mathrm{~cm}$ from the proximal jejunum corresponding to biliopancreatic or afferent loop. This loop measures, generally, around $75 \mathrm{~cm}(75-150 \mathrm{~cm}$ linearly in the largest BMIs) and is distally anastomosed to the jejunum - with a retro- or antecolic route - with the segment that allows the food transit, the efferent or Roux loop. This segment is composed of a superior, vertical or horizontal, small gastric pouch with an approximate volume capacity of $25 \mathrm{~mL}$ (2040 ), which is anastomosed proximally to the jejunum segment sectioned near its origin. Weight loss occurs mainly through a restrictive mechanism since the small gastric pouch and the narrow gastrojejunal transit create early and prolonged satiety. Malabsorption contributes to a lesser degree to the weight loss due to the bypass of the duodenum and the variable length of the proximal jejunum. These anastomoses can be associated with the emergence of internal hernias, as Petersen hernias and transmesenteric hernias, which may be favored by retrocolic anastomosis.

Vertical sleeve gastrectomy, in turn, is an essentially restrictive procedure performed in patients with morbid obesity as a first procedure before the advent of RYGB. Due to its ease of execution and no consequential anastomoses, in addition to providing satisfactory rates of weight loss, it was once the main procedure for bariatric surgery in the United States and worldwide. Technically, it consists of longitudinally dividing, via laparoscopic route and with the 
irreversible exclusion of curvature, the gastric fundus, body, and proximal antrum, an area that corresponds to approximately $70 \%$ to $80 \%$ of the stomach.

Regarding the immediate postoperative radiographic evaluation of these patients, the goal is usually to evaluate the possibility of leaks or obstructions in order to determine, for example, whether there is a need for urgent reexploration, or if there are any fistulas. The patency of gastrojejunostomy and jejunojejunostomy are analyzed, as well as the proper progression of the oral contrast material before the patient is discharged (usually 24-72 hours after surgery). The tomographic study also allows to assess late complications and is determinant in the detection and characterization of obstructions of the small intestine, due, for example, to twisting of the mesenteric root and internal hernias.

The technique for image acquisition by computed tomography is similar to that used in conventional exams for abdomen analysis.

The mAs factor is obtained automatically and the tension (KV) is adjusted to provide the optimum picture quality, limiting the radiation dose. The intravenous (IV) contrast is administered based on weight, similarly to patients of non-bariatric surgery, with a standard delay of approximately 70 seconds, which is the preferred and assists, in particular, in the detection of vascular complications and abscesses ${ }^{4.8}$.

The oral contrast assists in the detection of complications such as leakages and fistula routes. Given the reduction of functional gastric volume, usually, a smaller quantity of the oral contrast agent soluble in water should be used - approximately $60 \mathrm{ml}$ ingested immediately before the scan. The goal is to opacify the gastric pouch, as well as the adjacent output (proximal efferent loop) and not the entire length of the intestinal transit. The images are obtained through thin sectional slices, which are then reconstructed on the axial, coronal, and sagittal planes with a section approximately $3.0 \mathrm{~mm}$ thick. It is important to emphasize that the use of thin slices is fundamental to allow high-resolution multiplane reconstructions, assisting in the evaluation of the causes of obstruction of the small intestine and in the identification of findings of internal herniae, such as architectural distortion of the mesentery and adjacent vessels ${ }^{4,8,9}$.

\section{Fistulas}

The anastomotic leaks are early postoperative complications that can occur, generally, within ten days after the surgery in $6 \%$ of patients, requiring emergency surgical reexploration in $80 \%$ of the cases $^{10}$. Most postoperative leaks after RYGB extend to the upper left quadrant, to the left of the gastrojejunal anastomosis, but can also be present in the jejunojejunal anastomosis" ${ }^{11}$. Leaks may be small and self-limited, present in asymptomatic patients or in those with nonspecific symptoms, such as tachycardia, fever, and abdominal pain or even sepsis. More commonly observed after the gastric sleeve, $1 \%$ to $8 \%$ of the cases,

\section{FIGURE 1.}
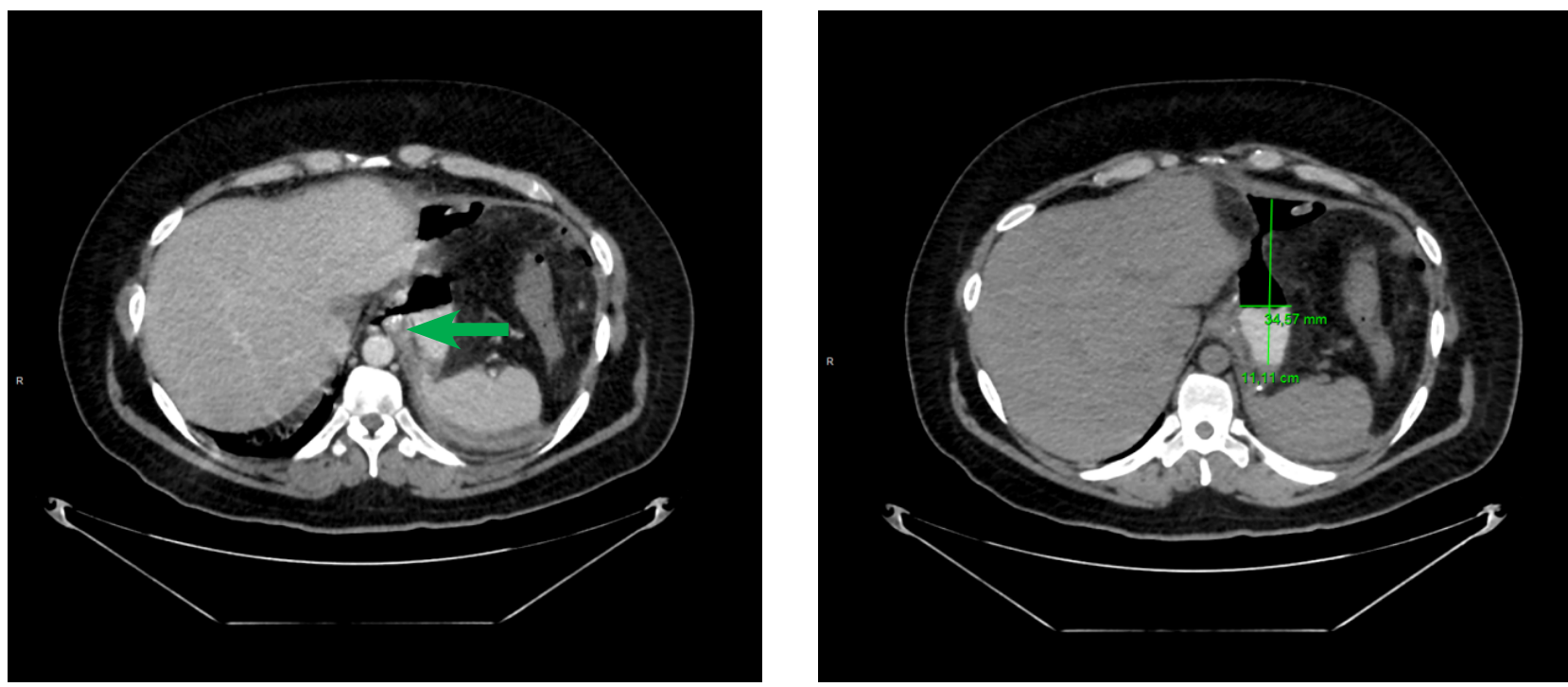

Image A - Collection (estimated measurement between the green calipers) located laterally to the gastric pouch, containing liquid and gas. There is a fistulous route (green arrow) between the gastric pouch and the collection, with extravasation of the contrast media administered orally. 
FIGURE 1.
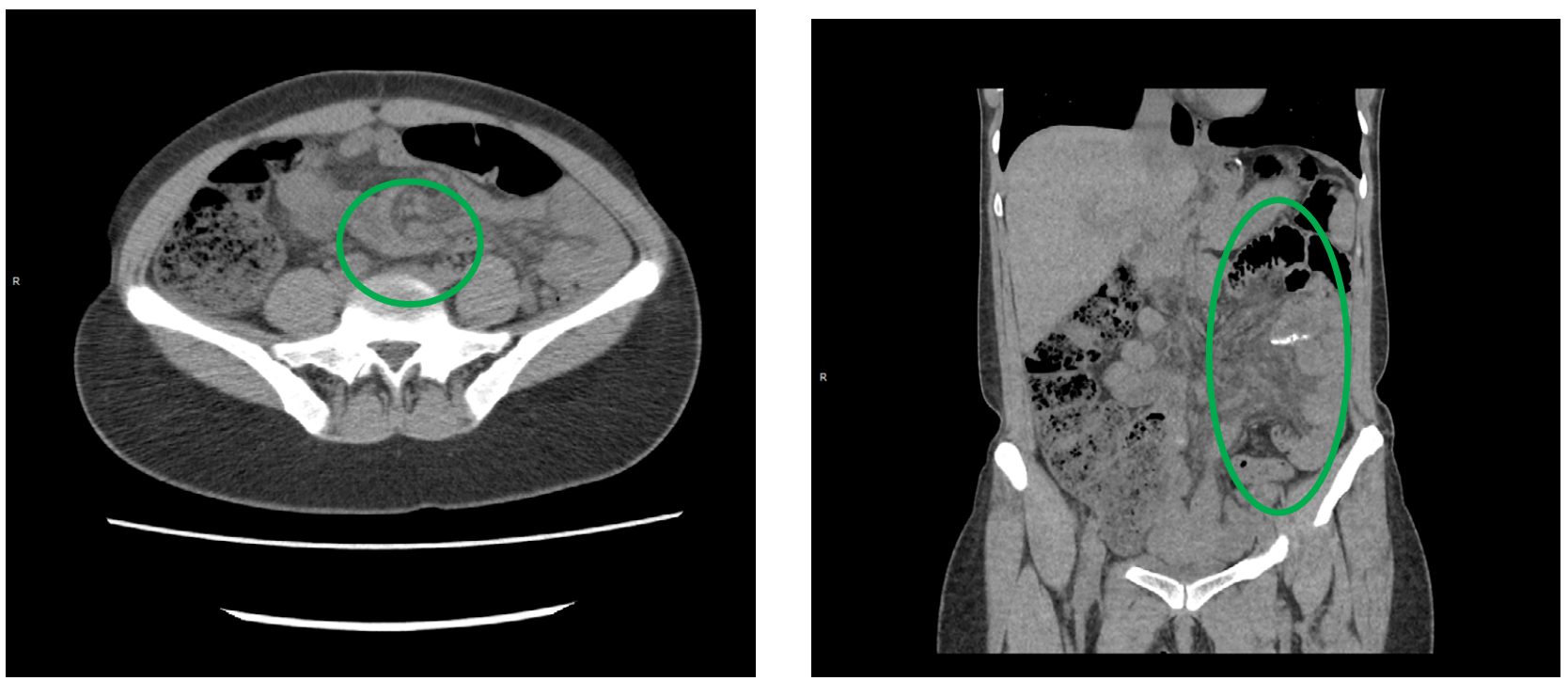

Image B - Internal hernia - axial and longitudinal cuts - twisting of the root of the mesentery, with "whirlpool sign" (circle) and "mushroom sign" (ellipse). Twisting of the axial mesentery in the epigastric region, with rotation of vessels, peritoneal adipose tissue and small intestine loops without significant distension or thickening of the walls.

and leading to significant morbidity, it is also possible after RYGB ${ }^{11.12}$. Therefore, early detection is essential to reduce this risk. Leaks occur most commonly in the proximal row of staples of the gastroesophageal junction (Figure 1) and may be caused by mechanical failure or ischemia. The CT may also show hematomas in the topography of the procedure or abscesses related to the fistulas ${ }^{6,8}$.

\section{SMALL INTESTINE OBSTRUCTION}

Obstructions of the small intestine are a relatively common complication after RYGB. Their incidence varied from $0.4 \%$ to $7.45 \%$ in a review of the subject ${ }^{11}$. Such obstruction may be caused by different mechanisms, such as: adhesions, internal hernias, hernias of the abdominal wall, anastomotic stenosis, and hematomas. The tomographic findings include dilated bowel loops upstream from the point of transit narrowing concomitant to the presence of distally collapsed loops ${ }^{4,9,11}$.

Such findings have a high correlation with the presence of internal hernias in patients post-RYGB.

Internal hernias can present both acutely and in the late postoperative period, occurring due to flaws in the mesentery, and the small intestine it thus herniated because of these flaws, usually toward the upper left abdomen, which predisposes to the occurrence of obstruction, ischemia, infarction, and even perforation. Internal hernias occur in about $3 \%$ of patients
post-RYGB and can be potentially fatal, occurring in both the early and late post-surgery period; however, they are more common in the latter,10,12. There are three different types of internal hernias that can occur after RYGB: 1 - through the mesocolon; 2 - in a potential mesenteric defect adjacent to the jejunojejunal anastomosis; and 3 - as Petersen hernias. Some characteristic defects of the mesentery may serve as potential sites for the development of internal hernias, among them: the defect created in the transverse mesocolon with the retrocolic Roux loop - which, despite minimizing tension on the anastomosis, is the most common site of occurrence of hernias -, the defect that develops adjacent to the jejunojejunal anastomosis, and the defect between the caudal margin of the mesocolon and the mesentery of the Roux loop, also called Petersen hernia ${ }^{1,3,9,12}$.

The best sign isolated for detecting an internal hernia was the "mesenteric whirlpool" sign ${ }^{9.13}$, which refers to the centripetal curvilinear appearance of the mesenteric vessels and fat in the mesenteric root of the small intestine. A greater correlation was obtained by the combination of this latter finding with the "mushroom" sign, which refers to the shape of the hernial content when it protrudes through the relatively narrow opening between the vessels and the mesenteric root. After crossing this narrowing, the content expands toward the left hypochondrium (Figure 1). Another finding that can assist in the identification of internal hernias is the displacement of the 
jejunojejunal anastomosis from its typical location, which would be on the left middle abdomen. As for the Petersen hernia (Figura 2), the herniated loop is characteristically found in the upper left quadrant of the abdomen, above the level of the stomach. Other findings that have also been described include: the displacement of the angle of Treitz anteriorly and to the right, as well as the presence of ileal loops with a descending route, originating in the upper left quadrant. The whirlpool and mushroom signs may be present but are less specific ${ }^{9.13}$.

\section{Intussusception}

Intussusceptions in the small intestine may be transient or fixed and are a rare cause of obstruction after gastric bypass surgery. They typically occur in the very jejunojejunal anastomosis or adjacent to it, with the line of staples presumably acting as the starting point for intussusception ${ }^{4}$. Reduced intestinal peristalsis or even ectopic peristaltic stimulation in the jejunum post-surgery can trigger dysfunctional retrograde contractions close to the anastomosis and operate as a contributing factor (Figure 2$)^{4.8}$.

\section{FIGURE 2.}
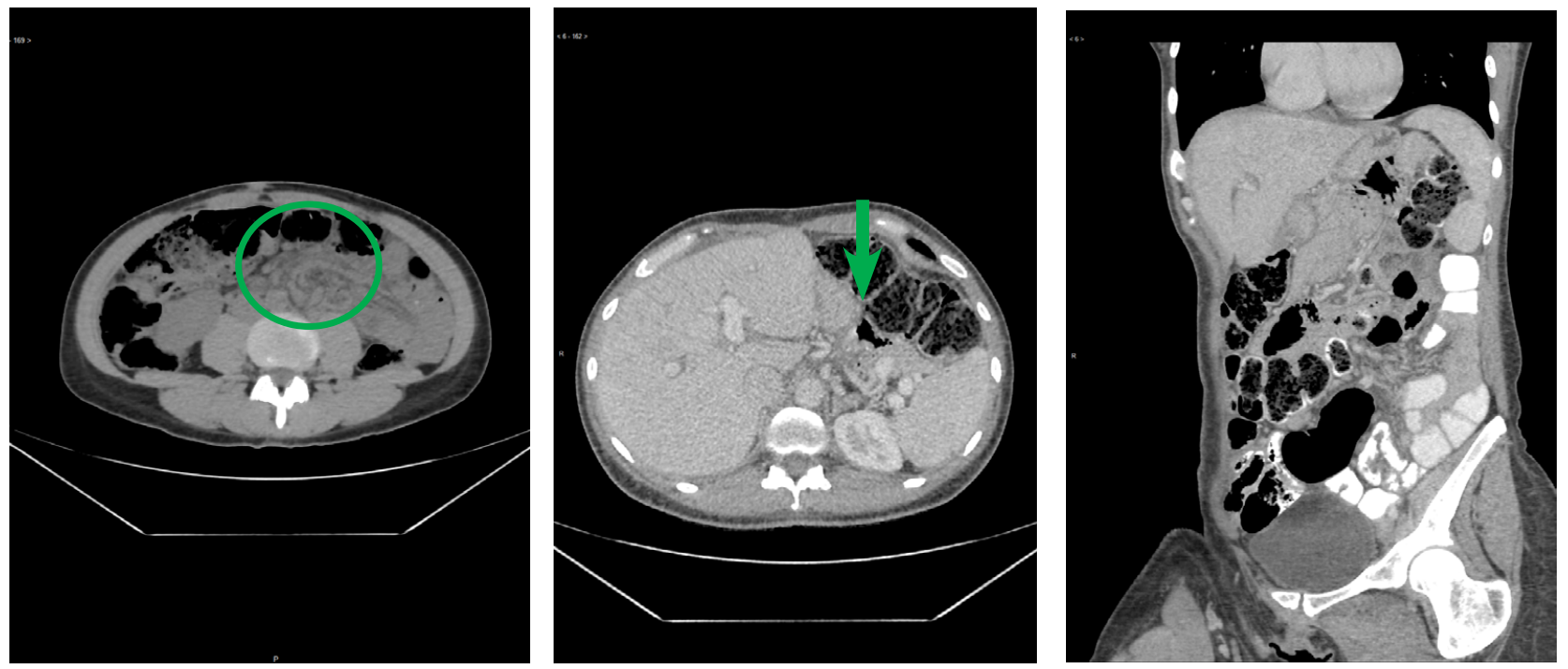

Image C - Petersen Hernia - axial planes and oblique sagittal reformatting: whirlpool sign - twisting of the root of the mesentery with a spiral effect of the vessels - circle. Internal hernia with small intestine loop interposed between the stomach and the colon (arrow and ellipse).
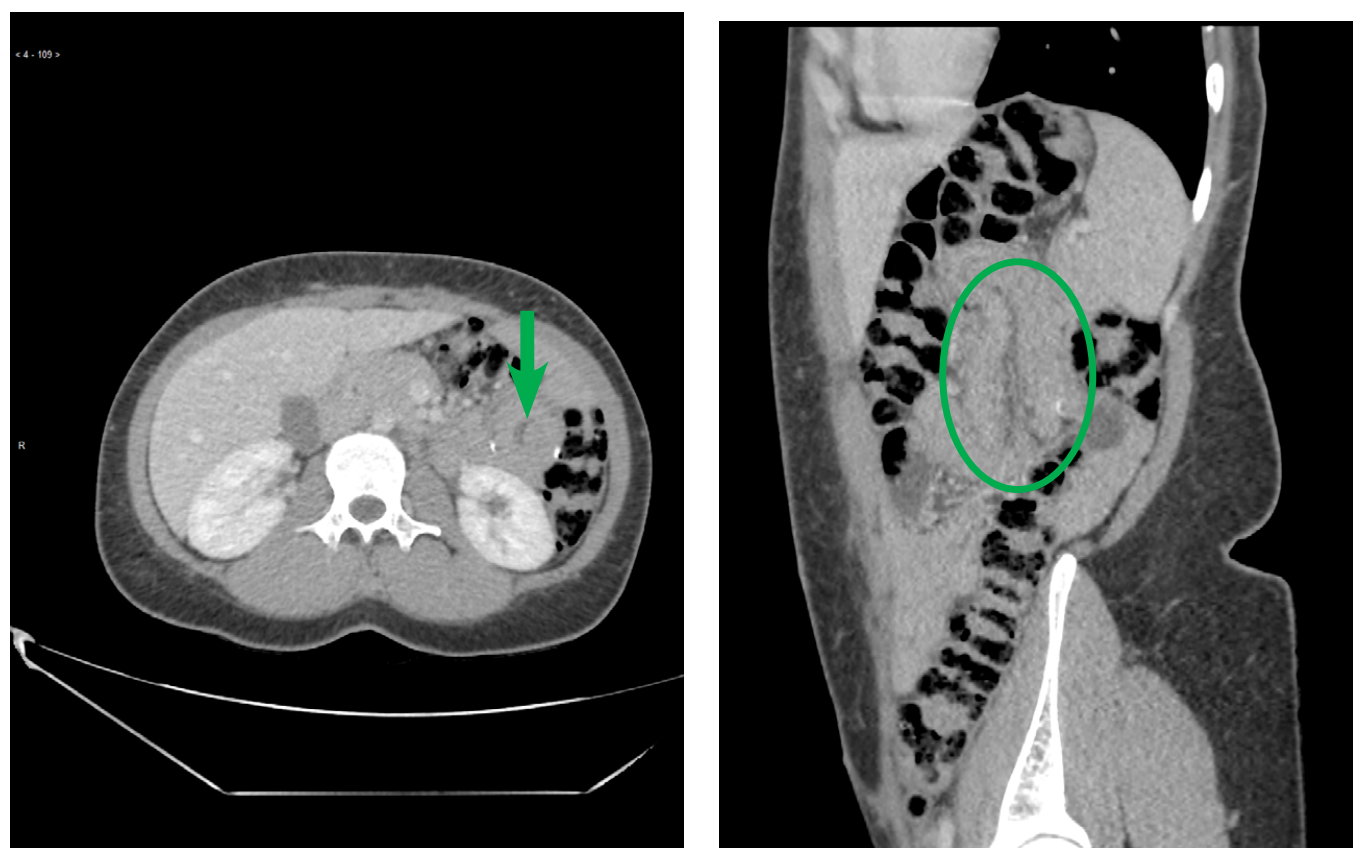

Image D - intestinal intussusception after gastric bypass - axial reformatting and in the oblique sagittal plane. Enlargement of the enteric anastomosis, with protrusion of the jejunal loops towards the inside, characterizing intestinal invagination - target aspect (arrow). Reformatting in the sagittal plane to assess the intussusception (ellipse). 


\section{Anastomotic stenosis}

Another complication that can also lead to obstruction and that was observed in our study was anastomotic stenosis. The anastomotic narrowing can be the result of reactional edema in the perioperative period and circular stapling of the jejunojejunal anastomosis, or it can manifest late, resulting from ischemia, bridles, or adhesions $\mathbf{s}^{\mathbf{1}, 2,5,6}$. The obstruction of the afferent loop is potentially fatal since a closed loop is created, in which there are no natural means for decompression of the segment, which can lead to gastric perforation and/or necrosis. Jejunojejunal anastomotic stenosis usually requires re-operation; however, it is much less common than gastrojejunal anastomotic stenosis (3\% to $9 \%$ ), occurring in $<0.9 \%$ of the cases and with the possibility of leading to small intestine obstruction ${ }^{1,3,10,12}$. This narrowing in the anastomosis presents in the CT as distending loops upstream the Roux segment, the biliopancreatic loop, or both ${ }^{1.4}$. CT may be particularly advantageous to

FIGURE 3.
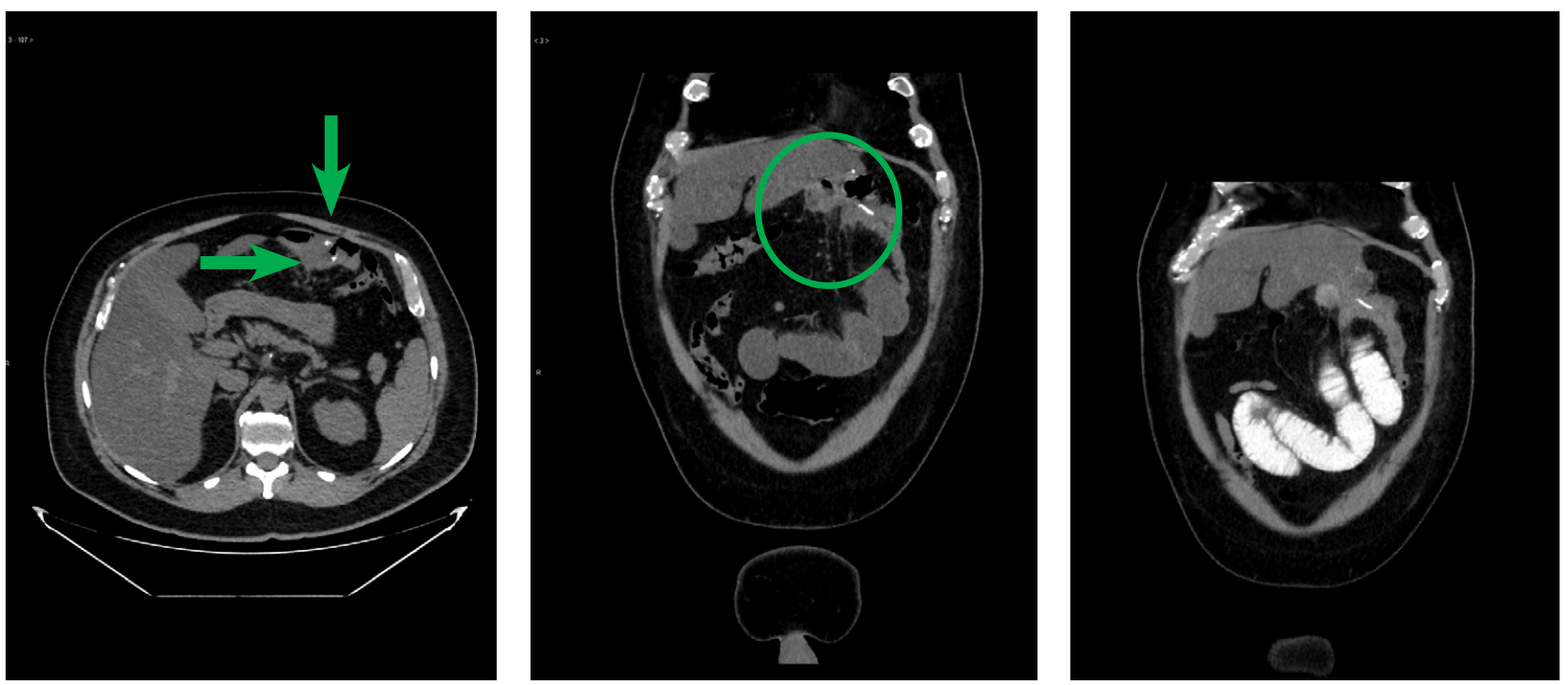

Image E - Jejunojejunal anastomosis with uppward displacement up until near the epigastric region (head of arrow). It is associated with light densification of adjacent adipose planes in this topography (arrow). It is possible to see moderate focal dilatation of the jejunal loops upstream of the anastomosis (circle ). After opacification of the digestive tube with the oral contrast, the focal dilatation of the jejunal loops is maintained upstream the anastomosis, without progression of the oral contrast beyond this level (ellipse). The aspect is compatible with intestinal obstruction, possibly related to birdles or adhesions.
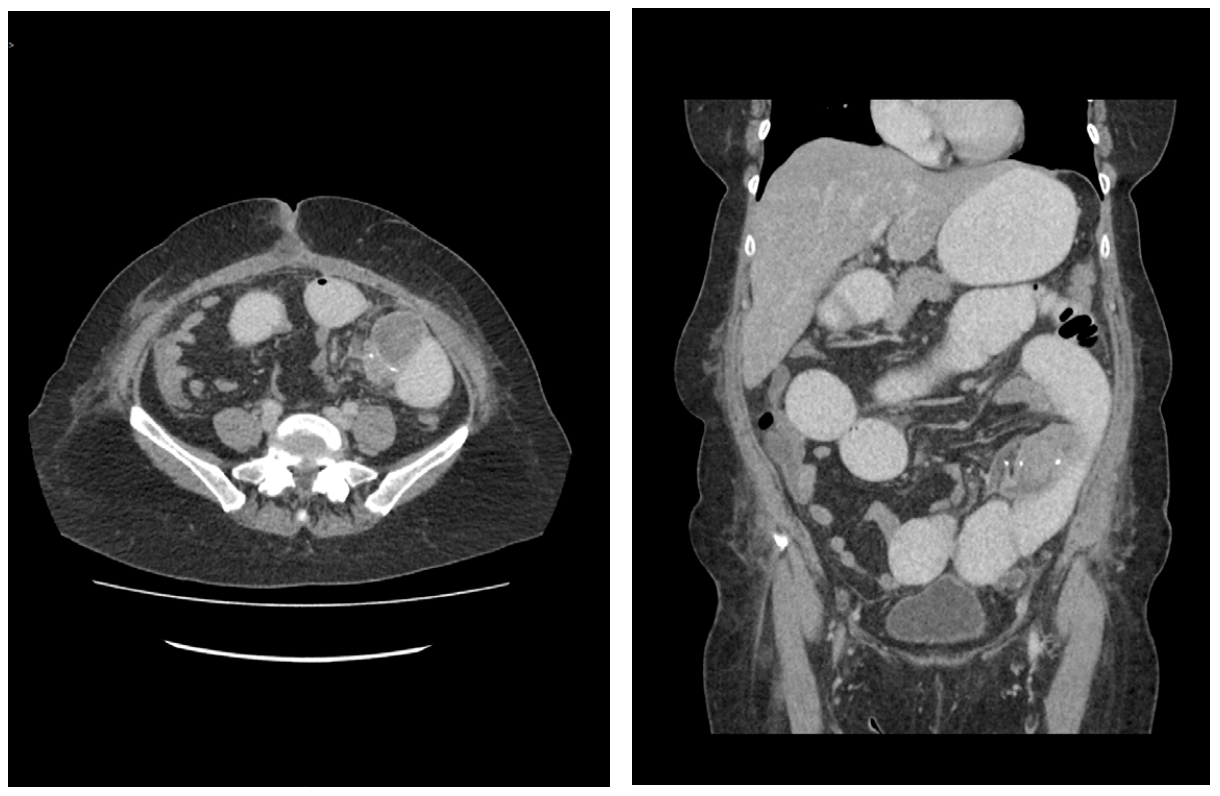

Image F - Jejunojejunal anastomotic stenosis. Distending small intestinal loops, with envolvment of the jejunal segments, distended by air-fluid content, with fecalization of its content in the distal third of the distension. A small focal/segmental area stands out with luminal narrowing in the enteroenteric anastomosis (arrow), without areas of significant parietal thickening identifiable with the method. Consequent absence of fecal and gas content in the colon (intestinal obstruction). There was no progression of contrast material beyond the anastomosis (circle). 
evaluate jejunojejunal anastomosis because it allows excellent evaluation of the biliopancreatic/afferent loop (Figure 3) 1,7,10 $^{1,}$

\section{Adjustable gastric banding / gastric ring}

The placement of the adjustable gastric bands/ rings generally is done laparoscopically and constitutes the placement of a ring around the proximal region of the stomach, sutured to the abdominal wall, usually $5 \mathrm{~cm}$ below the hemidiaphragm to restrict the passage of ingested food ${ }^{2.11}$. CT assists in the assessment of the correct positioning of the band and its possible shifting/migration due to the possible weakening or breakage of the sutures ${ }^{11}$. Other possible, but less frequent complications would be erosion and infection ${ }^{3.4}$.

\section{CONCLUSION}

Bariatric surgery has been increasingly prevalent in response to the obesity epidemic. Various techniques for surgical management are available for surgeons, and the role of radiologists is to be familiar with such procedures. Knowledge of the expected postoperative anatomy, major complications, and main image signs are fundamental for a precise diagnosis and to optimize patient care.

\section{Author's Contribution}

Raspante, L.B.P.; Barquette, A.C.; Motta, E.G.P.C, Ribeiro, M.A; Moreira, W.; Ramos, L.F.M.; contributed to the design and implementation of the research, to the analysis of the images, and to the writing of the manuscript.

\section{RESUMO}

A obesidade é uma doença crônica caracterizada pelo excesso de tecido adiposo no organismo e um verdadeiro problema de saúde pública. A cirurgia bariátrica, nas últimas décadas, ganhou espaço no seu tratamento devido à eficiência obtida na perda ponderal e redução importante de comorbidades relacionadas. Os procedimentos bariátricos mais comumente realizados incluem o bypass gástrico em Y-de-Roux, a banda gástrica ajustável e a gastrectomia vertical - Sleeve - por via laparoscópica. Entre as complicações possíveis descritas podem ser citadas: fístulas, deiscências, úlceras marginais, obstrução intestinal, hérnias internas e estenose de anastomoses. Essas complicações podem apresentar desfechos clínicos desfavoráveis, uma vez que os sintomas são frequentemente inespecíficos. A tomografia computadorizada de abdome (TC) constitui uma importante ferramenta na avaliação de complicações pós-operatórias, tanto no status pós-cirúrgico imediato quanto tardias, de pacientes submetidos a tal procedimento. Foram analisados os achados tomográficos mais ilustrativos das diferentes complicações pós-gastroplastia redutora ocorridas em 203 pacientes sem distinção de idade ou gênero. A correta interpretação requer que os radiologistas compreendam a técnica cirúrgica, uma vez que a anatomia pós-cirúrgica e as complicações específicas da cirurgia podem ser obstáculos para a adequada interpretação.

PALAVRAS-CHAVE: Gastroplastia. Cirurgia bariátrica. Complicações pós-operatórias. Tomografia computadorizada por raios X.

\section{REFERENCES}

1. Levine MS, Carucci LR. Imaging of bariatric surgery: normal anatomy and postoperative complications. Radiol. 2014;270(2):327-41.

2. Francisco MC, Barella SM, Abud TG, Vilar VS, Reibscheid S, Arasaki CH, et al. Análise radiológica das alterações gastrintestinais após cirurgia de Fobi-Capella. Radiol Bras. 2007;40(4):235-8.

3. Lehnert B, Moshiri M, Osman S, Khandelwal S, Elojeimy S, Bhargava P, et al. Imaging of complications of common bariatric surgical procedures. Radiol Clin North Am. 2014;52(5):1071-86.

4. Ximenes MAS, Baroni RH, Trindade R, Abdala R, Racy MCl, Moron RA, et al. Achados tomográficos na hérnia de Petersen como complicação de cirurgia bariátrica com bypass gástrico em $Y$ de Roux. Einstein. 2008;6(4):452-8.

5. Labrunie EM, Marchiori E, Tubiana IM. Anastomotic leaks after Roux-en-Y gastric bypass surgery by Higa's technique for treatment of morbid obesity: radiological findings. Radiol Bras. 2008;41(2):75-9.

6. Scheirey CD, Scholz FJ, Shah PC, Brams DM, Wong BB, Pedrosa M Radiology of the laparoscopic Roux-en-Y gastric bypass procedure: conceptualization and precise interpretation of results. RadioGraphics. 2006;26(5):1355-71
7. Trenkner SW. Imaging of morbid obesity procedures and their complications. Abdom Imaging. 2009;34(3):335-44.

8. Labrunie EM, Marchiori E. Obstrução intestinal pós-gastroplastia redutora pela técnica de Higa para tratamento da obesidade mórbida: aspectos por imagem. Radiol Bras. 2007;40(3):161-5.

9. Doishita S, Takeshita T, Uchima Y, Kawasaki M, Shimono T, Yamashita A, et al. Internal hernias in the era of multidetector CT: correlation of imaging and surgical findings. Radiographics. 2016;36(1):88-106.

10. Carucci LR, Turner MA. Imaging following bariatric procedures: Roux-en-Y gastric bypass, gastric sleeve, and biliopancreatic diversion. Abdom Imaging. 2012;37(5):697-711.

11. Riaz RM, Myers DT, Williams TR. Multidetector CT imaging of bariatric surgical complications: a pictorial review. Abdom Radiol. 2016;41(1):174-88.

12. Clayton RD, Carucci LR. Imaging following bariatric surgery: Roux-en-Y gastric bypass, laparoscopic adjustable gastric banding and sleeve gastrectomy. Br J Radiol. 2018;91(1089):20180031.

13. Dilauro M, Mclnnes MD, Schieda N, Kielar AZ, Verma R, Walsh C, et al. Internal hernia after laparoscopic Roux-en-Y gastric bypass: optimal CT signs for diagnosis and clinical decision making. Radiology. 2017;282(3):752-60. 